\title{
Research on the Optimization Strategy of the Construction of Aquatic Products Quality and Safety Traceability System in China
}

\author{
Ding Sun ${ }^{1, a}$ \\ ${ }^{1}$ Xi'an International University, Xi'an, Shaanxi, China, 710077
}

Keywords: Quality and Safety of Aquatic Products; Traceability System; Countermeasures and Suggestions

\begin{abstract}
Chinese aquatic product quality and safety traceability system is still in the initial stage of development and exploration period, in the local government's active efforts to promote and business cooperation, although also achieved some success, but also faced with many problems. Through combing and analyzing the problems in the construction of traceability system of aquatic products in China, the author puts forward the corresponding countermeasures and suggestions.
\end{abstract}

\section{The Construction Status Quo of Chinese Aquatic Product Quality and Safety Traceability System}

Through the detailed practice of aquatic product quality and safety traceability system in China, we can more clearly understand the process of the development of aquatic product quality and safety traceability system in China, what kind of problems exist, and perfect the establishment of a unified national aquatic product quality the need for a safe traceability system is more fully understood. Chinese practice and construction still remain in the relatively preliminary stage, mainly the local governments and enterprises in the tentative to carry out some small pilot and demonstration, began to rise to the national level last year, the practice of pilot, there are still many problems, the law Regulations, the actual operation of the existence of all sorts of deficiencies, but there are also worthy of the place, in recent years, the practice has also made some achievements.

\section{The Problems in Construction Practice of Chinese Aquatic Products Quality and Safety Traceability System}

The Relevant Laws and Regulations System and Standards Are Not Perfect. Chinese aquatic products can be traced back to the relevant special laws and regulations, aquatic product quality and safety supervision laws and regulations and aquatic products can be traced back to the laws and regulations mainly rely on the overall agricultural quality and safety management of agriculture-related laws and regulations or food Safety regulatory aspects of laws and regulations.

The Difficulties in Basic Information Collection. Chinese aquatic products industry is facing the status quo is the production of small producers and more large and medium-sized enterprise-type producers less, scattered production, the degree of intensive; coupled with fresh water products and sales-oriented, processing and Inadequate packaging, hygienic conditions and standardized operating procedures, as well as comprehensive inspection and quarantine conditions such as agricultural and livestock products are difficult to guarantee, the production standardization is insufficient.

The Lack of Relevant Technology and Equipment Research. Chinese aquatic product quality and safety traceability system construction process, the related technology and equipment research started late, the relative lack of research cannot effectively meet the quality and safety of aquatic products in China can be traced back to the needs of the system. There are many researches on related technologies in the world. The technology is more advanced and the technology is more advanced. Now there are some institutions and scholars based on the research results of foreign research or new technology and software development. The state and local governments have also made certain Support, from the current local pilot situation, the labels taken around the coding 
technology is not uniform, in some places to take a record and the way to check the ticket, this measure can be through the sales of aquatic product safety supervision and Through the product information management and access restrictions to protect the safety of aquatic products, but this initiative cannot be called a complete aquatic product quality and safety traceability system.

The Lack of Awareness of All Aspects of Society. Chinese aquatic product quality and safety traceability system of the construction process, the social concept of the formation of social and cultural atmosphere for the construction process is also very important to promote, and obviously the various aspects of our society on the relevant cognitive concept of the existing problems and errors. It is mainly the government side, the production process and the circulation of the participants, consumer awareness of aquatic product quality and safety traceability system and so on.

\section{The Recommendations of Construction of Chinese Aquatic Products Quality and Safety Traceability System}

In the construction of Chinese aquatic product quality and safety traceability system, the basic idea of this paper is: to set a reasonable principle of the premise of the premise, to laws and regulations, policies, standards as the main body of the three main components to market access and credit system for the protection of the market mechanism and signal display mechanism as the basic so that the main part of the interaction, play a function, the formation of operational mechanisms.

Set a Reasonable Goal. The overall goal of establishing a traceability system for aquatic products in China is to establish a fully traceable traceability system for traceability of aquatic products covering the whole society from production to sales, which can be traced back to aquatic products to water original supplier of raw material.

Establish Appropriate Principles. First, it is the principle of scientific and rationality. Scientific rationality principle requires the construction of aquatic product quality and safety traceability system, both the overall planning and specific implementation of the system must adhere to follow the scientific principles, follow the scientific laws.

Second, it is the principle of unity and flexibility. In the process of building Chinese aquatic product quality and safety traceability system, covering the whole society and the national characteristics of the outstanding decision of the system design in the planning and implementation process must do a unified requirement.

Third, it is the principle of economic efficiency. In the process of building our country's aquatic product quality and safety traceability system, we need to pay attention to the economy and the effectiveness, adopt the optimal and efficient means pay attention to economic and efficiency considerations.

Fourth, it is the principle of government and market cooperation. The construction of traceability system for aquatic products in China requires the joint efforts of government and market players. The government is responsible for planning and promoting and supervising. The market players follow the market mechanism.

Fifth, it is forward-looking principles. In the process of building our country's aquatic product quality and safety traceability system, we must pay attention to the forward-looking planning, that is, planning long-term, future-oriented, full consideration of Chinese social environment, policy environment, political environment, scientific and technological progress and other future development and the possible changes, the design system needs to leave room for reservations.

Establish and Improve the Legal System. The establishment of aquatic product quality and safety traceability system legal system is the aquatic product quality and safety traceability system can be legally run, effective and orderly development of the important protection and foundation. Therefore, we must establish and improve the safety of aquatic products can be traced back to the relevant laws and regulations system, making it an important guarantee for traceability of aquatic product quality and safety. In short, the construction of aquatic product quality and safety traceability system, the first is to establish and improve the relevant laws and regulations system. Through the establishment of a sound legal system, aquatic product quality and safety traceability 
of the implementation of the system can be effectively protected.

Establish and Improve the Policy System. The establishment of the policy system of traceability system for aquatic products in China is an indispensable and important support in the process of traceable system construction. It is a traceable system construction process and all the processes in the process of operation can cooperate with each other, effectively promote the traceability of the overall system can be carried out in an orderly and rapid and stable development of the important protection. Chinese aquatic product quality and safety traceability system of the policy system, including many aspects involve the construction of traceable system of the various subjects and links. The main role of the policy system is through the policy in all aspects of the policy and through policy support for the various parts of the system into the vitality or strengthen management, protection and support of aquatic product quality and safety traceability system of orderly operation and healthy development.

Establish and Improve the Standard System. It is an important prerequisite to establish the standard system of aquatic product safety traceability in the process of building traceability system of aquatic products in China. Traceability of the traceability of the system, the most critical is the safety of aquatic products can be traced back to the relevant information recording, storage and delivery, so aquatic products can be traced back to the relevant standards is critical, there is no relevant standards, unified security information will not be generated.

Coordinate the Functions of the Main Functions. The role of the main functions. The relevant functions of the relevant departments of the government in the process of establishing traceability of aquatic products can be divided into two parts, one is the direction of the main operation and standardize the order of operation, that is, the general direction, the development of aquatic product quality and safety traceability system objectives, all kinds of functional means to promote the system to build and improve the process, and through legal and policy means to develop the system needs to run the order of norms and rules, the other part is based on established rules and objectives responsible for the management of other entities in the system operation, order and direction of development.

The operational mechanism of traceability system. The proposed traceability system for aquatic product safety and safety is carried out in accordance with the following principles:

Promote Industry Organization and Standardization. Chinese aquatic products production and distribution chain should also strengthen the organization, intensive, standardized management, which is not only aquatic product quality and safety traceability system construction requirements, but also adjust and optimize the industrial structure, promote industrial upgrading is the inevitable direction of development is the inevitable requirement and trend of market economy development. To promote the production of intensive and standardized, the advantages of scale cluster will help improve the overall competitiveness of products and deal with market risk capabilities, is conducive to the development of new markets and sales channels to open up, is conducive to aquatic product brand building, standardized production more help improve product quality and safety, reduce costs and improve production efficiency. The organization of the organization will be conducive to the formation of production and sales of one-stop production of a complete chain, for reducing the cost of circulation, stable sales, is conducive to aquatic product quality and safety traceability system infrastructure construction process of the whole chain of information collection and traceability.

Strengthen the Construction of Aquatic Product Quality and Safety Credit System. Aquatic product quality and safety traceability system in the process of operation, to trace the aquatic product quality and safety information to determine the quality and safety of aquatic products is traceable information, so that traceability system can play a normal function and the role of information. Therefore, further improve the quality and safety of aquatic products can be traced back to the system, the need for a comprehensive establishment of the quality and safety of aquatic products, credit system construction, through the safety of aquatic products, production, circulation, sales of economic entities in the credit record constraints and supervision and credit rating, the subject of their own behavior constraints.

The Implementation of Aquatic Products Market Access System. The market access system 
is a system that strengthens the maintenance and management of the market economy order by strengthening the control of the products entering the market by setting a certain threshold standard for the goods entering the sales links. It is usually used to strengthen the quality of related products. In Chinese market economy in the process of operation, the market access system has a lot of space and room for the implementation of specific products through the market access, you can limit the design has a certain degree of quality indicators to meet certain requirements of the product can flow into the market is the product quality supervision and control from the production, circulation to sales in all aspects of the last threshold.

Strengthen the Relevant Technology Research and Development. The core of the traceability system lies in the information, the operation and function of the whole system are carried out around the information records, transmission and traceability, and focus on solving the problem of information asymmetry and missing; so the prominent feature of the retrospective system is the modern. The strong dependence of information science and technology, it can be said that without these technologies, traceability system will be primitive, inefficient, basically impossible to achieve. The United States first in the last century began to research and application of information encoding and transmission technology and its application, the realization of traceable system has laid a good foundation. Traceability of the core system to solve the problem is the transmission and recording of information. In order to facilitate the identification and recording of the machine, coding technology has become an indispensable part, and the corresponding carrier, read the system, the database is a set of technology, are indispensable.

\section{References}

[1] Fan Huiling, Zhao Kun; Cheng Xiaodong.Study on the construction of traceability system of agricultural products [J] Shaanxi Agricultural Sciences, 2012 (9)

[2] Li Linna, Chen Wen, Song Gui, Fang Jincen, Huang Lei, Meng Di. Aquatic product quality and safety and traceability system establishment and application [J].China Aquatic Products, 2009 (3)

[3]Shelley Clarke. Understanding Chinese fish trade and traceability[M]. Hong Kong, China:TRAFFIC East Asia, 2009.

[4]Brian L.Buhr. " Traceability and Information Technology in the Meat Supply Chain: Implications for Firm Organization and Market Structure”[J]. Journal of Food Distribution Research 2003(34) 